\title{
Cognitive ability in childhood and cognitive decline in mid-life: longitudinal birth cohort study
}

Marcus Richards, Beverly Shipley, Rebecca Fuhrer and Michael E J Wadsworth

BMJ 2004;328;552-; originally published online 3 Feb 2004; doi:10.1136/bmj.37972.513819.EE

Updated information and services can be found at: http://bmj.com/cgi/content/full/328/7439/552

These include:

References This article cites 16 articles, 5 of which can be accessed free at: http://bmj.com/cgi/content/full/328/7439/552\#BIBL

3 online articles that cite this article can be accessed at: http://bmj.com/cgi/content/full/328/7439/552\#otherarticles

Rapid responses 3 rapid responses have been posted to this article, which you can access for free at:

http://bmj.com/cgi/content/full/328/7439/552\#responses

You can respond to this article at:

http://bmj.com/cgi/eletter-submit/328/7439/552

Email alerting Receive free email alerts when new articles cite this article - sign up in the service box at the top right corner of the article

Topic collections Articles on similar topics can be found in the following collections

Psychogeriatrics (141 articles)

Other Epidemiology (1601 articles)

Dementia (505 articles)

Socioeconomic Determinants of Health (823 articles)

\section{Notes}




\title{
Papers
}

\section{Cognitive ability in childhood and cognitive decline in mid-life: longitudinal birth cohort study}

\author{
Marcus Richards, Beverly Shipley, Rebecca Fuhrer, Michael E J Wadsworth
}

\begin{abstract}
Objective To examine the association between cognitive ability in childhood and mid-life cognitive decline in the normal population.

Design Longitudinal, population based, birth cohort study. Participants 2058 men and women born in 1946.

Main study measures Ability in childhood measured by AH4 and test of verbal comprehension at age 15 years. Ability in adulthood measured by the national adult reading test (NART) at age 53 years. Outcome measures were decline in memory (word list learning) and speed and concentration (timed visual search) from age 43 to 53 years.

Results Ability in childhood was significantly and negatively associated with decline in memory $(\beta=0.09, \mathrm{P}=0.005$, for men; $0.10, \mathrm{P}<0.001$, for women) and search speed ( $\beta=0.13$, $\mathrm{P}<0.001$, for men; $0.08, \mathrm{P}=0.01$, for women), independent of educational attainment, occupational social class, and a range of health indicators. The adult reading test was also significantly and negatively associated with decline in these outcomes (for memory $\beta=0.21, \mathrm{P}<0.001$, for men; $0.17, \mathrm{P}<0.001$, for women; and for search speed $\beta=-0.05$ for men; 0.10 , $\mathrm{P}=0.008$ for women) independent of educational attainment, social class, and childhood ability.

Conclusions Ability in childhood can protect against cognitive decline in mid-life and beyond. Results for the adult reading test indicate that the protective effect of ability may also be acquired in adulthood.
\end{abstract}

\section{Introduction}

Cognitive decline is associated with functional impairment ${ }^{1}$ and is a risk factor for frank dementia. ${ }^{2}$ Considerable effort has therefore been invested in identifying its causes. While sociodemographic factors have been examined, ${ }^{3}$ much less is known about the lifetime influence of cognitive ability. Lower ability in childhood ${ }^{4}$ and early adulthood ${ }^{5}$ is associated with increased risk of dementia, but the influence of early ability on general cognitive decline is less understood. A recent study found no difference in rate of cognitive change throughout life according to estimated level of early ability. ${ }^{6}$ Using data from the British birth cohort we investigated the association between measured ability in childhood and rate of decline in memory, speed, and concentration in mid-life, controlling for educational and occupational attainment. Because cohort members had been administered the national adult reading test (NART) at the age of 53 years we were also able to investigate possible independent effects of ability in childhood and adulthood on rate of decline in these measures.

\section{Methods}

The 1946 birth cohort-Participants were drawn from the MRC national survey of health and development (NSHD), a birth cohort study stratified by social class and initially consisting of 5362 born in England, Scotland, and Wales during one week in March 1946. ${ }^{7}$ Information about sociodemographic factors and medical, cognitive, and psychological function has been repeatedly obtained by interview and examination, most recently in 1999, when cohort members were aged 53 years and the sample size was 3035. At this time the cohort was fairly representative of the UK population ${ }^{8}$ except that more of those who did not respond had never married and were least advantaged in terms of cognitive ability, educational attainment, and social class.

Cognitive measures -At the age of 15 years cohort members took the Heim AH4 test ${ }^{9}$ and the Watts-Vernon reading test. ${ }^{10}$ The AH4 is a 130 item ability test, with verbal (analogies, comprehension, and numerical reasoning) and non-verbal items (matching, spatial analysis, and non-verbal reasoning) summed to yield a general ability score. The Watts-Vernon is a test of reading comprehension that requires selection of appropriate words to complete 35 sentences. At the ages of 43 and 53 cohort members were given repeat tests of memory (a three trial 15 item word list) and speed and concentration (timed letter search). To minimise practise effects, parallel forms were used for both tests. At the age of 53 they also took the national adult reading test $\left(\mathrm{NART}^{11}\right)$. Before statistical analysis all test scores were standardised to give a mean of 0 and a standard deviation of 1 .

Educational and occupational attainment-The highest educational qualifications and their training equivalents attained by the age of 26 were classified as none, vocational only, ordinary secondary (O levels, equivalent to current GCSE), advanced secondary (A levels), or degree level or equivalent. Current or last occupational social class at the age of 53 was classified according to the registrar general's system.

Statistical methods-We used linear regression to investigate the association between ability in childhood and decline in memory and search speed between the ages of 43 and 53 years (model 1). Conditional models of change were used to assess decline, by adjusting the memory and speed scores at 53 years for their corresponding scores at 43 years. We then adjusted associations for educational attainment and occupational social class (model 2), entered as categorical variables. To investigate the independent effect of mature ability on any decline, we further adjusted associations for the adult reading test score (model 3). All cognitive scores were entered as standardised variables, after formal tests confirmed assumptions of linearity. To investigate whether any associations between ability and decline 
Table 1 Unadjusted means (SD) for cognitive test scores and frequency distributions (number (percentage)) for educational attainment and occupational social class

\begin{tabular}{lcccc} 
Variable & Males $(\mathbf{n}=\mathbf{1 0 0 4})$ & Females & $(\mathbf{n}=\mathbf{1 0 5 4})$ \\
\hline AH4 at age 15 years & $77.69(17.91)$ & $76.07(17.48)$ \\
\hline NART at age 53 years & 34.46 & $(9.53)$ & 34.16 & $(9.17)$ \\
\hline Memory: & & & & \\
\hline 43 years & 24.32 & $(5.80)$ & 25.91 & $(6.22)$ \\
\hline 53 years & 23.20 & $(6.14)$ & 25.06 & $(6.11)$ \\
\hline Search speed: & & & & \\
\hline 43 years & 332.32 & $(76.64)$ & 352.14 & $(74.75)$ \\
\hline 53 years & 271.72 & $(72.35)$ & 288.80 & $(74.50)$ \\
\hline Education: & & & & \\
\hline No qualifications & 326 & $(32.5)$ & 361 & $(34.3)$ \\
\hline Vocational & 62 & $(6.2)$ & 102 & $(9.7)$ \\
\hline Ordinary secondary & 157 & $(15.6)$ & 291 & $(27.6)$ \\
\hline Advanced secondary & 304 & $(30.3)$ & 246 & $(23.3)$ \\
\hline Higher & 155 & $(15.4)$ & 54 & $(5.1)$ \\
\hline Occupational social class: & & & & \\
\hline I & 124 & $(12.4)$ & 19 & $(1.8)$ \\
\hline II & 398 & $(39.6)$ & 367 & $(34.8)$ \\
\hline III non-manual & 102 & $(10.2)$ & 374 & $(35.5)$ \\
\hline III manual & 280 & $(27.9)$ & & $(8.0)$ \\
\hline IV & 79 & $(7.9)$ & 156 & $(14.8)$ \\
\hline V & 21 & $(2.1)$ & 54 & $(5.1)$ \\
\hline
\end{tabular}

NART=national adult reading test.

were explained by health, we further adjusted these models, in turn, for smoking, alcohol consumption, affective state, body mass index, exercise, resting pulse, systolic and diastolic blood pressure, and forced expiratory volume in one second $\left(\mathrm{FEV}_{1}\right)$ at 43 and 53 years.

\section{Results}

\section{Missing data}

Of the 3035 cohort members interviewed at 53 years, 2058 (1004 men and 1054 women) had complete data for ability at 15 years, educational attainment, adult social class, memory and search speed at 43 and 53 years, and the adult reading test score at 53 years. Those with missing data for any of these variables had lower ability scores at the age of 15 than those with complete information $(\mathrm{P}<0.001)$. Table 1 shows means and frequency distributions for these variables, separately for males and females.

\section{Childhood ability and decline in memory}

Table 2 shows regression coefficients $(\beta)$ for the association between AH4 score at the age of 15 and decline in memory from 43 to 53 years. Positive coefficients indicate that higher AH4 scores were associated with slower decline in memory in men and women (model 1). The magnitude of this association was reduced after we adjusted for education and social class (model 2) and reduced further after additional adjustment for the reading test score at 53 years (model 3), although the AH4 remained independently associated with decline below the $1 \%$ significance level after all these adjustments.

We saw a similar pattern when we repeated these analyses using Watts-Vernon comprehension instead of the AH4 (data not shown), with higher score associated with slower decline in memory after we adjusted for education, social class, and the reading test score in men (regression coefficient $0.12,95 \%$ confidence interval 0.05 to $0.19, \mathrm{P}<0.001)$ and women $(0.10,0.04$ to $0.17, \mathrm{P}=0.003$ )

\section{Childhood ability and decline in search speed}

Table 3 shows regression coefficients for the association between AH4 score at the age of 15 and decline in search speed from 43 to 53 years. Again, higher AH4 scores were associated with slower decline in speed in men and women (model 1), although adjustment for education and social class (model 2) had less of an attenuating effect than it did on the association between $\mathrm{AH} 4$ and memory. For men this was also true when we additionally adjusted for the reading test (model 3), although it attenuated the effect for women.

For men, Watts-Vernon comprehension was not associated with decline in search speed after we adjusted for education and social class $(0.00,-0.07$ to $0.06, \mathrm{P}=0.93)$. For women this score remained significantly associated with decline in search speed after adjustment $(0.09,0.02$ to $0.16, \mathrm{P}=0.01)$, although this was no longer the case after we additionally adjusted for the adult reading test score $(0.03,-0.06$ to $0.11, \mathrm{P}=0.52)$.

\section{Adult ability and cognitive decline}

Correlations between the $\mathrm{AH} 4$ and adult reading test score were 0.59 for men and 0.55 for women. For men and women higher adult reading test scores were associated with slower decline in memory, independent of the AH4 (table 2). These associations were also independent of Watts-Vernon comprehension (data not shown) and of similar magnitude. In women only the adult reading test score was inversely associated with decline in speed $(\mathrm{P}=0.008$, table 3$)$. This was also the case when we substituted the Watts-Vernon score for the AH4 score. Overall, a 10 point decrease in raw adult reading test score corresponded to 1.4 word increase in memory decline, after we controlled for AH4, education, and occupation, and a 2.1 letter increase in search speed decline. Figures for the AH4 itself were 0.3 and 4.2, respectively. AH4 and reading test scores together accounted for $3 \%$ of the variance for memory decline and $1 \%$ of the variance for search speed decline, after we controlled for education and occupation.

\section{Education, social class, and health}

Increasing educational attainment was associated with slower decline in memory in men and women, independent of ability in childhood (model 2). These associations were attenuated when we adjusted for the reading test score (model 3), particularly in men. Occupational social class had a negligible independent effect on memory decline (see table 2).

There was no independent association between education and decline in search speed (table 3). This was also the case for social class, although in men there was a trend for slower decline with higher occupational attainment.

Coefficients representing associations between ability and decline were not significantly altered when we adjusted, in turn, for smoking, alcohol consumption, affective state, body mass index, exercise, pulse, blood pressure, and forced expiratory volume in one second at 43 or 53 years.

\section{Discussion}

In this prospective birth cohort study we found that measured ability in childhood was inversely associated with rate of decline in memory, speed, and concentration in mid-life, independent of socioeconomic and health status. Ability in adulthood was also inversely associated with decline in mid-life, independent of childhood ability.

\section{Strengths and weaknesses of this study}

Strengths of this study are the availability of measured ability in childhood and data on a range of potential confounders and the 
Table 2 Regression coefficients (95\% confidence intervals) representing rate of decline in memory per unit increase in AH4 ability score at age 15 . Positive coefficients indicate slower decline

\begin{tabular}{|c|c|c|c|c|}
\hline & \multicolumn{2}{|c|}{ Men } & \multicolumn{2}{|c|}{ Women } \\
\hline & Coefficient & $P$ value & Coefficient & P value \\
\hline \multicolumn{5}{|l|}{ Model 1} \\
\hline $\mathrm{AH} 4$ at 15 years & $0.23 \quad(0.17$ to 0.28$)$ & $<0.001$ & $0.22 \quad(0.17$ to 0.26$)$ & $<0.001$ \\
\hline \multicolumn{5}{|l|}{ Model 2} \\
\hline $\mathrm{AH} 4$ at 15 years & $0.16 \quad(0.10$ to 0.22$)$ & $<0.001$ & $0.15(0.10$ to 0.20$)$ & $<0.001$ \\
\hline \multicolumn{5}{|l|}{ Education: } \\
\hline No qualifications (reference) & 0 & $<0.001^{*}$ & 0 & $<0.001^{\star}$ \\
\hline Vocational & $-0.04(-0.25$ to 0.16$)$ & 0.69 & $0.06(-0.10$ to 0.21$)$ & 0.49 \\
\hline Ordinary secondary & $0.21 \quad$ (0.06 to 0.37$)$ & 0.007 & $0.30 \quad(0.18$ to 0.42$)$ & $<0.001$ \\
\hline Advanced secondary & $0.20 \quad(0.06$ to 0.34$)$ & 0.005 & $0.38 \quad(0.24$ to 0.52$)$ & $<0.001$ \\
\hline Higher & $0.33 \quad$ (0.15 to 0.52$)$ & $<0.001$ & $0.41 \quad(0.17$ to 0.65$)$ & $<0.001$ \\
\hline \multicolumn{5}{|l|}{ Occupational social class: } \\
\hline I (reference) & 0 & $0.16^{*}$ & 0 & $0.14^{\star}$ \\
\hline II & $-0.04(-0.19$ to 0.12$)$ & 0.66 & $0.06(-0.27$ to 0.38$)$ & 0.74 \\
\hline III non-manual & $0.11(-0.10$ to 0.32$)$ & 0.31 & $0.04(-0.29$ to 0.38$)$ & 0.80 \\
\hline III manual & $-0.26(-0.44$ to -0.07$)$ & 0.006 & $-0.05(-0.41$ to 0.31$)$ & 0.79 \\
\hline IV & $0.00(-0.23$ to 0.23$)$ & 0.99 & $-0.04(-0.40$ to 0.30$)$ & 0.80 \\
\hline V & $0.07(-0.29$ to 0.43$)$ & 0.70 & $-0.05(-0.44$ to 0.33$)$ & 0.79 \\
\hline \multicolumn{5}{|l|}{ Model 3} \\
\hline $\mathrm{AH} 4$ at 15 years & $0.09 \quad(0.03$ to 0.15$)$ & 0.005 & $0.10 \quad(0.05$ to 0.16$)$ & $<0.001$ \\
\hline NART at 53 years & $0.21 \quad(0.15$ to 0.27$)$ & $<0.001$ & $0.17 \quad(0.11$ to 0.23$)$ & $<0.001$ \\
\hline \multicolumn{5}{|l|}{ Education: } \\
\hline No qualifications (reference) & 0 & $0.04^{*}$ & 0 & $<0.001^{*}$ \\
\hline Vocational & $-0.08(-0.28$ to 0.12$)$ & 0.45 & $0.01(-0.15$ to 0.16$)$ & 0.91 \\
\hline Ordinary secondary & $0.14(-0.01$ to 0.29$)$ & 0.07 & $0.21 \quad(0.09$ to 0.34$)$ & $<0.001$ \\
\hline Advanced secondary & $0.11(-0.03$ to 0.25$)$ & 0.12 & 0.25 (0.11 to 0.40$)$ & $<0.001$ \\
\hline Higher & $0.19 \quad(0.00$ to 0.38$)$ & 0.05 & $0.26 \quad(0.02$ to 0.50$)$ & 0.03 \\
\hline \multicolumn{5}{|l|}{ Occupational social class: } \\
\hline I (reference) & 0 & $0.55^{*}$ & 0 & $0.54^{\star}$ \\
\hline II & $-0.01(-0.16$ to 0.14$)$ & 0.90 & $0.08(-0.25$ to 0.40$)$ & 0.65 \\
\hline III non-manual & 0.12 (-0.09 to 0.32$)$ & 0.27 & $0.08(-0.26$ to 0.42$)$ & 0.63 \\
\hline III manual & $-0.17(-0.36$ to 0.01$)$ & 0.06 & $0.01(-0.36$ to 0.37$)$ & 0.97 \\
\hline IV & $0.04(-0.18$ to 0.27$)$ & 0.72 & $0.04(-0.31$ to 0.40$)$ & 0.81 \\
\hline V & $0.13(-0.23$ to 0.48$)$ & 0.48 & $0.01(-0.38$ to 0.39$)$ & 0.97 \\
\hline
\end{tabular}

NART=national adult reading test.

${ }^{*} \mathrm{P}$ for trend.

use of repeated cognitive measures in mid-life. The latter is of interest as it shows cognitive decline at a considerably earlier time in life than is often assumed, although the proportion of this decline explained by ability was small. It will be important to determine, therefore, whether this proportion increases as the cohort ages.

However, we consider that our study had several limitations. Firstly, there was a high loss to follow up, which limits generalisability. There was also a disproportionate loss to follow up of those with low cognitive ability, although there is no reason to believe that this bias altered the pattern of association between ability and decline. Secondly, to date we have obtained repeated measures for only two cognitive tasks in this cohort, albeit those of functional importance, and so we were unable to determine whether the association between early ability and cognitive decline is general or confined to specific cognitive domains. Thirdly, from an ageing perspective this is still a relatively young cohort, and the functional consequences of cognitive decline in mid-life are unclear. It is a reasonable assumption, however, that as these people approach later life, those of lower ability may be at increased risk of clinically important cognitive decline.

Our results are contrary to those of Rabbitt et al, ${ }^{6}$ who did not find an association between ability in childhood and rate of $\operatorname{cog}$ nitive decline in mid to later life. However, these authors estimated childhood AH4 scores, on the assumption that childhood vocabulary score can be estimated from adult vocabu- lary score, and that childhood vocabulary score is, in turn, a proxy for childhood AH4. While there is little doubt that these assumptions are broadly true, our results show that they may not be precise enough for accurate prediction of cognitive decline.

\section{Interpretation}

Why should those of lower ability decline more rapidly? Deary et al have reviewed the evidence that high ability may increase the likelihood of entry into a healthy and stimulating environment that preserves cognitive ability in maturity. ${ }^{12}$ Indeed, healthy behaviour, including exercise ${ }^{13}$ and not smoking, ${ }^{14}$ can modify the rate of cognitive decline in this cohort. However, neither these variables nor a range of other health indicators nor socioeconomic status explained the association between ability and rate of decline, suggesting that accumulation of independent risk factors in those of lower ability is not the reason for the inverse association between ability and decline. It may be that cognitive ability directly reflects properties of the central nervous system, such as processing speed and capacity, which determine rate of decline associated with age, particularly in tasks that require effort and concentration. ${ }^{15}$

The association between early ability and cognitive decline raises questions about the determinants of early ability itself. These include genetic influence, ${ }^{16}$ the uterine environment, ${ }^{17}{ }^{18}$ and home conditions. ${ }^{19}{ }^{20}$ These factors will have to be 
Table 3 Regression coefficients (95\% confidence intervals) representing rate of decline in visual search speed per unit increase in AH4 ability score at age 15. Positive coefficients indicate slower decline

\begin{tabular}{|c|c|c|c|c|}
\hline & \multicolumn{2}{|c|}{ Men } & \multicolumn{2}{|c|}{ Women } \\
\hline & Coefficient & $P$ value & Coefficient & $P$ value \\
\hline \multicolumn{5}{|l|}{ Model 1} \\
\hline $\mathrm{AH} 4$ at 15 years & $0.14 \quad(0.09$ to 0.20$)$ & $<0.001$ & $0.12 \quad(0.07$ to 0.18$)$ & $<0.001$ \\
\hline \multicolumn{5}{|l|}{ Model 2} \\
\hline $\mathrm{AH} 4$ at 15 years & $0.11 \quad(0.05$ to 0.17$)$ & $<0.001$ & $0.11 \quad(0.05$ to 0.18$)$ & $<0.001$ \\
\hline \multicolumn{5}{|l|}{ Education: } \\
\hline No qualifications (reference) & 0 & $0.99^{*}$ & 0 & $0.30^{*}$ \\
\hline Vocational & $-0.06(-0.30$ to 0.17$)$ & 0.60 & $0.05(-0.15$ to 0.24$)$ & 0.63 \\
\hline Ordinary secondary & $-0.10(-0.28$ to 0.08$)$ & 0.26 & $0.05(-0.10$ to 0.20$)$ & 0.49 \\
\hline Advanced secondary & $0.00(-0.16$ to 0.16$)$ & 0.98 & $0.06(-0.11$ to 0.23$)$ & 0.51 \\
\hline Higher & $-0.03(-0.24$ to 0.19$)$ & 0.81 & $0.17(-0.11$ to 0.46$)$ & 0.24 \\
\hline \multicolumn{5}{|l|}{ Occupational social class: } \\
\hline I (reference) & 0 & $0.02^{\star}$ & 0 & $0.53^{*}$ \\
\hline II & $-0.01(-0.18$ to 0.17$)$ & 0.93 & $-0.02(-0.44$ to 0.39$)$ & 0.91 \\
\hline III non-manual & $-0.06(-0.30$ to 0.17$)$ & 0.60 & $0.00(-0.42$ to 0.43$)$ & 0.98 \\
\hline III manual & $-0.19(-0.39$ to 0.02$)$ & 0.08 & $0.01(-0.45$ to 0.47$)$ & 0.97 \\
\hline IV & $-0.17(-0.43$ to 0.09$)$ & 0.20 & $-0.02(-0.46$ to 0.42$)$ & 0.94 \\
\hline V & $-0.28(-0.68$ to 0.13$)$ & 0.18 & $0.13(-0.35$ to 0.61$)$ & 0.60 \\
\hline \multicolumn{5}{|l|}{ Model 3} \\
\hline AH4 at 15 years & $0.13 \quad(0.06$ to 0.20$)$ & $<0.001$ & $0.08 \quad(0.02$ to 0.15$)$ & 0.01 \\
\hline NART at 53 years & $-0.05(-0.12$ to 0.03$)$ & 0.21 & $0.10 \quad(0.02$ to 0.17$)$ & 0.008 \\
\hline \multicolumn{5}{|l|}{ Education: } \\
\hline No qualifications (reference) & 0 & $0.76^{\star}$ & 0 & $0.91^{*}$ \\
\hline Vocational & $-0.06(-0.29$ to 0.18$)$ & 0.64 & $0.02(-0.18$ to 0.22$)$ & 0.84 \\
\hline Ordinary secondary & $-0.08(-0.26$ to 0.10$)$ & 0.36 & $-0.01(-0.16$ to 0.15$)$ & 0.92 \\
\hline Advanced secondary & $0.02(-0.14$ to 0.18$)$ & 0.78 & $-0.03(-0.21$ to 0.15$)$ & 0.74 \\
\hline Higher & $0.01(-0.21$ to 0.23$)$ & 0.92 & $0.06(-0.23$ to 0.36$)$ & 0.67 \\
\hline \multicolumn{5}{|l|}{ Occupational social class: } \\
\hline I (reference) & 0 & $0.01^{*}$ & 0 & $0.27^{*}$ \\
\hline II & $-0.01(-0.19$ to 0.16$)$ & 0.89 & $-0.01(-0.42$ to 0.40$)$ & 0.96 \\
\hline III non-manual & $-0.07(-0.30$ to 0.17$)$ & 0.59 & $0.03(-0.39$ to 0.45$)$ & 0.89 \\
\hline III manual & $-0.21(-0.42$ to 0.00$)$ & 0.05 & $0.05(-0.41$ to 0.50$)$ & 0.84 \\
\hline IV & $-0.18(-0.44$ to 0.08$)$ & 0.18 & $0.04(-0.40$ to 0.48$)$ & 0.84 \\
\hline V & $-0.30(-0.70$ to 0.12$)$ & 0.16 & $0.17(-0.31$ to 0.65$)$ & 0.49 \\
\hline
\end{tabular}

NART=national adult reading test.

${ }^{*} \mathrm{P}$ for trend.

investigated to determine the extent to which they have a long term effect on cognitive ageing.

Finally, it is worth emphasising that mature ability may confer its own protection against cognitive decline. This supports the findings of an earlier report that this measure is inversely associated with incidence of dementia, ${ }^{21}$ as well as with decline in ability itself. ${ }^{12}$ We have shown that this effect is independent of childhood ability. While this may reflect stable but different aspects of ability, it is also consistent with observations that verbal skills can increase up to the eight or ninth decade ${ }^{22}$ and may therefore offer a protection against decline that can be acquired in adulthood. Preliminary observations in this cohort suggest that job training and adult education can augment verbal ability. In view of our findings this is clearly a topic that requires detailed investigation.

Contributors: MR conceived and designed the study, conducted the analyses, drafted and revised the paper, and is guarantor. All contributors discussed the design of the analyses and the core issues of the study and helped to revise the paper.

Funding: The Medical Research Council provided funding for the MRC National Survey of Health and Development, and financial support for MR, BS, and MEJW. McGill University financially supported RF.

Competing interests: None declared.

Ethical approval: North Thames Multicentre Research Ethics Committee.

1 Moritz DJ, Kasl SV, Berkman LF. Cognitive functioning and the incidence of limitation in activities of daily living in an elderly community sample. Am J Epidemiol 1995; 141:41-9.
2 Brayne C, Best N, Muir M, Richards SJ, Gill C. Five-year incidence and prediction of dementia and cognitive decline in a population sample of women aged $70-79$ at base-

3 Lee S, Kawachi I, Berkman LF, Grodstein F. Education, other sociodemographic indicators, and cognitive decline. Am J Epidemiol 2003;157:712-20.

4 Whalley LJ, Deary IJ. Longitudinal cohort study of childhood IQ and survival up to age 76. BMJ 2001;322;819-22.

\section{What is already known on this topic}

A recent study found no association between estimated IQ in childhood and rate of decline in later life

It is unclear whether IQ in later life predicts rate of cognitive decline

\section{What this study adds}

Measured IQ in childhood was significantly and negatively associated with decline in memory, speed, and concentration in mid-life

This association remained after adjustment for educational attainment, occupational social class, and a range of health indicators

Adult IQ was also significantly and negatively associated with decline, also independently of childhood IQ, education, social class, and health 
5 Snowdon DA, Kemper SJ, Mortimer JA, Greinier LH, Wekstein DR, Markesbery WR Linguistic ability in early life and cognitive function and Alzheimer's disease in later life findings from the nun study. JAMA 1996;21:528-32.

6 Rabbitt P, Chetwynd A, McInnes L. Do clever brains age more slowly? Further exploration of a nun result. BrJ Psychol 2003;94:63-71.

7 Wadsworth MEJ. The imprint of time: childhood, history and adult life. Oxford: Clarendon Press, 1991.

8 Wadsworth MEJ, Butterworth SL, Hardy R, Kuh D, Richards M, Langenberg C, Connor M. The life course design: an example of benefits and problems associated with study longevity. Soc Sci Med (in press).

9 Heim AW. The AH4 group test of intelligence. Windsor: NFER-Nelson, 1970.

10 Pigeon DA. Details of the fifteen years tests. In: Douglas JWB, Ross JM, Simpson HR, Pigeon DA. Details of the fifteen years te

11 Nelson HE, Willison JR. National adult reading test (NART). 2nd ed. Windsor: NFER-Nelson, 1991

12 Deary IJ, MacLennan WJ, Starr JM. Is age kinder to the initially more able?: differential ageing of a verbal ability in the healthy old people in Edinburgh study. Intelligence 1999;26:357-75

13 Richards M, Hardy R, Wadsworth MEJ. Does active leisure protect cognition? Evidence from a national birth cohort. Soc Sci Med 2003:56:785-92.

14 Richards M, Jarvis MJ, Thompson N, Wadsworth MEJ. Cigarette smoking and cognitive decline in midlife: evidence from a prospective birth cohort study. Am J Public Health 2003;93:994-98.

15 Salthouse TA. The processing speed theory of adult age differences in cognition. Psychol Rev 1996;103:403-28.

16 Plomin R. Genetics and general cognitive ability. Nature 1999;402 (6761 suppl):C25-9.

17 Berger A. Insulin-like growth factor and cognitive function. BMJ 2001;322:203.
18 Wellberg LAM, Seckle JR. Prenatal stress, glucocorticoids and the programming of the brain.J Neuroendocrinol 2001;13:113-28.

19 Douglas JWB. The home and the school. London: MacGibbon \& Kee, 1964.

20 Rutter M. Family and school influences on cognitive development.J Child Psychol Psychiatry 1995;26:683-704.

21 Schmand B, Smit JH, Geelings, Lindeboom J. The effect of intelligence and education on the development of dementia. Psychol Med 1997;27:1337-44.

22 Rabbitt P. Does it all go together when it goes? QJ Exp Psychol 1993;46(A):385-433.

(Accepted 27 November 2003)

doi 10.1136/bmj.37972.513819.EE

MRC National Survey of Health and Development, Department of Epidemiology and Public Health, University College London, London WC1E 6BT Marcus Richards MRC scientist

Michael E J Wadsworth professor

Department of Epidemiology and Public Health, University College London Beverly Shipley MRC research student

Department of Epidemiology, Biostatistics and Occupational Health, McGill University Faculty of Medicine, 1020 Pine Avenue West Montreal QC, Canada H3A 1A2

Rebecca Fuhrer professor

Correspondence to: M Richards m.richards@ucl.ac.uk 